\title{
O vestido vermello da avoa Carmen
}

\author{
Vanesa Rodríguez TEMBRÁS
}

Cando a miña avoa me dixo que tiña que falar seriamente comigo, a verdade é que pensei que quería discutir termos da herdanza. Eu xa sabía que era o seu olliño dereito, pero non podía imaxinarme que fora ela mesma a que falase de deixarme tódolos seus aforros que, por certo, debían de ser uns cantos; xa que a muller non gastaba case nada e cobrara unha boa morea de cartos cando morrera meu avó.

Meu avó Ramiro, aínda que ninguén da familia o sabiamos, pagaba un seguro de vida moi substancioso. Todo un misterio. A cantidade segue sendo unha incógnita. Descubrímolo cando miña avoa comezou a traer á casa xogos de potas, coitelos franceses e incluso unha PlayStation, xa que abrira distintas contas bancarias cos cartos do seguro. «Son todos uns ladróns, así que se queren roubarme, non levarán a bola enteira, senón só un anaco», dicía a avoa Carmen. Carmen co " $n$ " mudo. O mesmo que o "d" do Django de Tarantino.

Non se pode esquecer neste reconto do testamento tódalas fincas da familia, moitas delas sorprendentemente moi cotizadas, xa que os da cidade non paran de vir facer unha casiña na aldea; os currunchos de monte cheos de madeira para vender e, por último, a casiña restaurada da parroquia de Teixido. Todo isto é o que querería explicarme en vida, sen esperar ó seu derradeiro alento. Pensei tamén que, pobriña ela, debería sentirse moi soa desde que o avó falecera. Sentiría morrer pensando o soa que está na vida. Tiña preparado un pequeno diálogo no caso de que comezara a laiar: «Ai, o meu pobre home, o meu Ramiriño, cantas cousas nos quedaron por facer!». Eu diríalle para comeza-lo meu discurso: «Avoa Carmen, aquí estou eu, tamén meus pais... a túa propia filla, miña nai; e o resto da familia para axudarte. Non estás soa no mundo!».

Non é porque o escribira eu, pero saírame un diálogo de compensación inesquecible. A miña avoa podía firma-lo testamento sen a máis mínima dúbida. Eu era a súa tranquilidade. O seu legado. Sentíame a mellor e a máis cobizosa neta do mundo enteiro. Cegárame na miña propia cobiza, sen chegar a preguntarme o porqué de que miña avoa non lle deixara a súa herdanza á súa única filla, miña nai, e pasase directamente á súa única nena, ou sexa, eu mesma. Eu xa me imaxinaba facendo unha viaxe polo mundo enteiro, como homenaxe á miña avoa, que tantas veces suspirara vendo os documentais de viaxes da sobremesa.

Cheguei ó seu cuarto cando xusto viñera da misa. O seu cuarto estaba na miña propia casa; xa que, desde que morrera meu avó, trouxerámola de Teixido a vivir con nós. $\mathrm{O}$ cuartiño da miña avoa sempre ulía a lavanda e a laca da permanente. Cheiraba que fedía a vello e sempre estaba ás escuras. Ulía a cerume de candeas, a unha colcha de satén verde augamariña dos anos sesenta, con faldóns arrepiantes que caían nas ladeiras da cama; a mobles de castiñeiro que estaban cheos de pastillas contra a traza con arrecendo a lavanda. O cuarto era interior, que fixeramos dividindo o salón, polo que non tiña fiestra. Tiña un ambiente de igrexa asfixiante. Estaba cheo de tallas de virxes de tódolos lugares donde estivera nas excursións do Imserso, ás que ía sempre soa con dúas amigas, que faleceran non había moito. 
Desde que morrera meu avó Ramiro, facía uns dous anos, decidiu pór loito e só abandonaba o seu cuarto para comer, ir á misa e, desde facía uns tres meses, ir ó local social da terceira idade que ten o concello na Praza das Telleiras.

Ela dicía que era divertido ver «como bailaban os vellos». Escachaba coa risa ó relatar como Vidal do Paipengo, o irmán de Vidaliño, o que tiña a ferraxería, acaneaba o cu coma se tivese formigas nel, e que sempre se achegaba ás viuvas máis novas.

Nos últimos días, non faltaba a ningunha cita e non paraba de contar historias cada vez máis atrevidas. «Sabes o marido da difunta Maruja da Curbeira, a irmá da que ten a mercería ó lado do Café Santiagho?... Si, oh! O zapateiro de Mureira... Se o viras, mimadriña, iso era para ver! E dálle, e dálle, bailando unha desas pezas modernas, si oh! Sabela, ti escoitas diso... un reghato deses... un raghatón, iso, iso, un baile moderno de raghatón. Pois aí estaba o zapateiro de Mureira, viúvo da que en paz descanse Maruja da Curbeira, dálle e dálle, para arriba e para abaixo. Refregha que refregha coa cantante do grupo Harmonía, que vén un sábado si e outro non. E xa me dirás ti, para que? Por moito que refreghe, aí xa non vive ninghén. Por moito que teña ghanas de abri-la gaiola, alí xa non hai paxaro que voe máis».

Miña avoa Carmen era para ver contando esa historia. Ríase como nunca a vira rir en moitos anos, inda co meu avó Ramiro vivo. El era un home serio que o máis divertido que facía coa súa muller na semana era ver a repetición de Luar dos domingos pola tarde, xa que segundo el: «o venres bótano moi tarde e non me gusta quedarme durmido no sofá».

O caso é que, alí estaba eu, ó carón da porta do cuarto da avoa Carmen. Ela estaba sacando do refaixo o pano branco bordado, donde todos sabiamos que gardaba os cartos. Estaba cambiando o loito de festa polo loito de diario. Sentei sobre a colcha augamariña, que soaba a papel engurrado. "Sabeliña, non sentes tan cómoda, que imos falar á terraza. A ti tamén che fai falta un pouco de raios de sol nesa cara de difunto que me tes. Non me estraña, todo o día chantada diante do ordenador, chateando, sen ver a luz do día».
Eu non daba crédito. A miña avoa utilizando o termo "chatear", a miña avoa Carmen querendo ir á terraza para recibir raios de sol cheos de vitamina $\mathrm{D}$, a miña avoa chiscándome un ollo.

Collemos dous tallos. Estabamos soas na casa, xa que meu pai estaba traballando e miña nai fora a un curso de macramé no local da asociación de veciños do barrio. Ía iniciar a miña disertación, cando a avoa Carmen soltoume: «Se queres, podes fumar un pitillo. Xa sei que o fas ás aghachadas, pero a min dácheme ighual». Se xa estaba branca antes, sen suficiente dose de vitamina $\mathrm{D}$, agora parecería un cadáver sentado nun tallo. «Avoa, eu... eu non fumo», acertei a pronunciar. «Bueno, muller, o que ti dighas. Eu só che digho que a min tanto che me ten. Fuma aghora, que logho virá túa nai».

Pero quen era esa muller de permanente grisácea que estaba diante miña. $\mathrm{O}$ que estaba segura, é que non era a miña avoa Carmen da parroquia de Teixido. "Avoa, eu quería decirche antes de nada que eu sempre estarei aquí para axudarche, que non estás soa...». O meu diálogo de apoio xa tomara corpo, cando a avoa Carmen paroume de súpeto. «Pois xustamente precisaba a túa axuda, Sabeliña, xa sabes que eres a miña neta favorita, a única, tamén é certo». A miña avoa cruzaba as pernas e entrelazaba as mans dun xeito que nunca fixera. A ela íalle máis a posición reflexiva e submisa coas pernas ben xuntas tapadas cun mandilón de corpo enteiro a cadros grises e negros, falando sempre coa cabeza agachada. Percateime de que xa non levaba o mandil nin as medias de media perna, que destacaban cunha cor distinta á da pel. «Ti dirás, avoa, sabes que non te decepcionarei. Serei o teu legado...», respondinlle chea de fachenda. Ela miroume con cara de estrañeza, engurrando o entrecexo; o cal, por certo, estaba libre de peliños por primeira vez en moito tempo. «A ver, muller, o que che quero pedir é que me axudes a mercar un vestido. Eu non sei onde ir na cidade. Vou casar o mes que vén»». Estaba paralizada, entrárame unha suor fría. Quedárame só co «vou casar». A avoa Carmen seguiu coas súas demandas: "Quero un vestido polo xeonllo, que non sexa branco, que xa non é cor para min; pero outra cor que non sexa neghro, que loito xa tiven dabondo». 
Eu seguía coa teima do «vou casar» a facer pinchacarneiros na miña cabeza. «Cerra a boca, Sabeliña, que aínda vas comer unha mosca. Entón, que dis?».

Estaba tan en shock que só acertei a dicirlle: «e que cor che gusta a ti?». «A min dácheme un pouco ighual, pero quizais vermello, a Reinaldo ghústalle moito o vermello. Di que as mulleres ghaleghas son quentes como o vermello. Pero algho eleghante, oíches? Non quero parecer un semáforo»».

Reinaldo. Vermello. Quentes. A avoa Carmen. Agora si que precisaba un pitillo. E aquela muller, á que na vida anterior coñeceramos como a miña avoa de Teixido, sabíao tanto coma min: «Colle o tabaco, muller, que aínda che ha de dar algho».

Reinaldo era o que tocaba o teclado no grupo Harmonía. Viñera de Cuba facía dous anos para gañar cartos e poder volver, deste xeito, á illa para montar un pequeno negocio e sustentar a súa familia. Tiña trinta e cinco anos e una nena, xa non tan nena, de quince; a cal quedara a vivir coa avoa. A nai da filla morrera de cancro pouco antes de que el se viñera para Galicia. A súa situación estábase complicando en España, polo que precisaba a nacionalidade canto antes, xa que non podía ir á súa terra máis que por tres meses e, polo visto, tampouco quedarse en Europa. «É un bo home, Sabela. Así que lle ofrecín casarmos e que así puidera regularizar os seus papeis no país».

Prendín un pito. A primeira calada foi tan fonda, que me mareei un pouco. A miña avoa seguía rindo, arqueando o carrelo cara atrás, mentres agarraba un xeonllo entrámba-las mans. «Como lle metas outro viaxe coma ese, xa o tes mamado enteiro! Ai! Tan valente e tan miñaxoia, miña nena! Non é para tanto, muller!».

As miñas mans tremían, acaneando o pitillo sen control. «Pero ti, pero ti, avoa... Pero logo non ves que ese cubano quere conseguir os papeis contigo e só che quere polos cartos?». Eu berreille á miña avoa sen compaixón, pero ela non perdeu o sorriso e contestoume con serenidade: «E logho ti, Sabeliña, por que crías que che mandara chamar? Que querías de min?». Levanteime do tallo que botaba lume. «Pero ti, pero ti que dis? Eu quérote, avoa e estaste equivocando! Ai, cando o saiba mamá!».

A miña avoa deu a conversación por rematada dicindo: «Miña neniña, pensa o que queiras. Aquí todos queredes levar tallada e aínda non estou metida no furado. Por suposto que Reinaldo quere casar para conseghi-los papeis, e logho, non comecei explicándoche iso? E non te equivoques, neniña, os cartos polo do momento son meus e farei deles o que me pete. Pero se vas durmir mal esta noite direiche, para a túa tranquilidade, que todos levaredes tallada. Polo de aghora, pagharei os billetes de quen queira ir á voda». "Os billetes do autobús de liña, ou que?», engadín eu botando o fume para fóra. «Ai, como se me vai a cabeza, miña nena! Esquecín decirche que a voda é en Cuba!».

Volvín sentar no tallo. Prendín outro pito, sen importarme que escoitara á miña nai entrar na casa. «Xa estou aquí, xa volvín! O demo me leve que volva colle-lo autobús para vir de macramé, iso é morrer a prazos!».

Cando chegou á terraza comezou a berrarme polo tabaco, estaba fóra de si, nunca me vira fumar antes. "Ai, xa verás cando llo conte a teu pai, vaiche cae-lo pelo, miña nena!». Eu nin tan sequera a mirei á cara, seguía coa mirada perdida no monte que se vía ó lonxe pola terraza. "Mamá, a avoa vai casar en $\mathrm{Cu}$ ba o mes que vén cun cubano que se chama Reinaldo».

Miña nai achegouse a min e tiroume o pitillo no chan, berrando coma unha tola. «Ai, cando llo conte a Manolo, a súa filla fumando porros deses diante da miña nai! E ti, non lle podías dicir nada, mamá? Tes unha neta droghadicta que xa está alucinando!».

Miña avoa abrazou a miña nai e, sen perder o ton de voz calmo, explicoulle: «Remedios, a nena non é droghadicta. Alghún porro probaría, non digho que non; pero tódolos novos o fan. Xa comprei os billetes para a voda. Quen non queira ir, que vaia á axencia de Pepe, o fillo de Carmela dos Xuncos, e que anule o billete e o seu cuarto. Pelei patacas para o xantar. Tamén saquei raxo do conxelador»». 
A avoa Carmen aloumiñaba o lombo de miña nai como se estivera limpando unha fiestra. A miña nai botou a chorar. Eu chorei tamén, pero sen tanto drama como miña nai. A miña avoa foi ve-la televisión, xa que, segundo ela, «con tanta parvada que tiñamos entrámbolas dúas, ía perde-lo parte». Miña nai sentou no mesmo tallo onde estaba a miña avoa e díxome entre bágoas, cun fío de voz: «Tes un para min?».

Catro semanas despois vimos á miña avoa dicir «sí, quiero» na sala principal do concello do pobo de Reinaldo en Villa Clara. De Galicia foramos poucos, os demais, dicían, non querían apoiar esa parvada. A voda foi ás once da maña e despois comemos un xantar, digno de galegos comellóns, nunhas mesas postas ó carón da praia.

A festa durou case dous días enteiros. Miña nai, que a levaba o demo, foise para o hotel sen toma-lo café. A miña avoa, que metera unha botella de caña de herbas na equipaxe, con dous chupiños acabou bailando unha muiñeira co seu novo sogro, co cal era vinte anos máis novo que ela. Estaba impoñente co seu vestido vermello. Non sei como explicalo, pero refulxía toda ela. Era unha beleza sen idade.

Meu pai sentou nunha mesa chea de mulleres cubanas, amigas da familia, bebendo ron a morro, preguntándolles se os cubanos eran tan bos na cama coma no baile. «No te preocupes por tu suegra, Manuel; Reinaldo la respeta y le estará eternamente agradecido».

$\mathrm{Eu}$ fun das últimas en abandonar o barco, bailando, diría a avoa Carmen, "raghatóns" cos invitados que ían quedando. Alí só se cansaban os galegos. Quen me ensinaba a move-lo corpo teso era a filla de Reinaldo, unha rapaza do máis xeitosa que me dixo quería estudar Enxeñaría en España.

Agora que recordo todo isto, bótoa de menos dunha maneira exaxerada. A avoa Carmen deixounos onte e pediume que vos contara hoxe, no seu enterro, unha historia para que a coñecerades como o comecei a facer eu aquel día na terraza.

Hoxe estamos aquí, todos os que quixemos vir; para entendela, para aprender dela, para respetala. Ela descubriu un significado novo do verbo "vivir", xa que nunca é tarde para facelo. En cada país que visitou con Reinaldo, o seu derradeiro amigo, o home que a ensinou a rir de novo, mandábame postais nas que dicía cousas moi da avoa Carmen: «Aquí en China comen moito arroz, pero ningunha pataca. Podes aborrecer algo, por moito que che guste, se o comes tódolos días. Hoxe en día, grazas a Deus, non hai necesidade diso. Dálle saúdos á familia. Coida do gato». 